\title{
Does Transparency Matter? The Impact of Provider Quality and Cost Information on Health Care Cost and Preventive Services Use
}

\begin{abstract}
Background: We tested whether provider quality and cost information had a meaningful impact on health care quality and costs at two large employers that introduced a transparent provider profiling system in 2006. Using retrospective claims from enrollees representing 3,928 covered lives in these two firms where the insurer was the sole provider of health insurance, we addressed two questions: 1) Did patients switch to higher quality and more efficient doctors when the provider rankings became available? 2) What is the effect of switching on total expenditures, out-of-pocket expenditures, and use of preventive services?
\end{abstract}

Methods: We used nonlinear regression to identify factors associated with improvement in quality and cost efficiency of providers seen by covered enrollees. We used difference-in-differences regression to test the impact on expenditures and use of preventive services of those who switched to higher-rated physicians.

Results: Age, illness burden, and female are positively associated with improvement in provider quality and efficiency. Provider portfolio improvement had a negative impact on expenditures, but the story with respect to prevention is mixed: preventive visits go up when the patient has an improved provider portfolio, but utilization of diagnostic screening procedures goes down.

Conclusions: A common concern in medical markets is the lack of information for consumers to shop for health care. We find consumers exhibit behaviors that suggest they use such information when it is available and useful. These results suggest that consumers could process additional price and quality information to gain more value from their health insurance benefits.

Keywords: Health insurance; Health economics; Managed care; Consumer behavior; Cost and quality transparency; Physician profiling

\section{Stephen T Parente ${ }^{1 *}$, Roger Feldman ${ }^{2}$ and Lewis Sandy ${ }^{3}$}

1 Carlson School of Management, University of Minnesota, 321 19th Avenue South, Room 3-279, Minneapolis, MN 55455, USA

2 School of Public Health, Division of Health Policy and Management, University of Minnesota, USA

3 UnitedHealth Group, 9900 Bren Road Minnetonka, USA

*Corresponding author: Stephen T. Parente

\section{Stephen.parente@gmail.com}

Carlson School of Management, University of Minnesota, 321 19th Avenue South, Room 3-279, Minneapolis, MN 55455, USA.

Tel: $612-624-1391$

Citation: Parente ST, Feldman R, Sandy L (2019) Does Transparency Matter? The Impact of Provider Quality and Cost Information on Health Care Cost and Preventive Services Use. J Health Med Econ Vol.5 No.1:3

Received: June 20, 2019; Accepted: August 12, 2019; Published: August 16, 2019

\section{Introduction}

A central limitation of healthcare markets is the lack of readily accessible and usable information to compare the cost and quality of medical providers and technologies. Much of the problem is the complexity of medical care. But another part of the problem is the accessibility of summary information on health care quality. Recently, this lack of information has fueled a call for 'transparency' in metrics on provider quality and efficiency. This drive for transparent information coupled with a postulate by Herzlinger [1] and others that consumers will change their health care consumption when this information is available through the Internet present an opportunity for an empirical test. This paper tests whether consumers will use new sources of transparent provider quality and cost information and how use of such information affects health care cost and utilization of preventive services.

Other than some web sites that provide hypothetical cost impacts from changing a prescription from brand to generic drugs, or switching from a retail pharmacy to mail-order, information on cost and quality transparency is not available to most consumers. One exception is medical provider rankings based on quality and cost-efficiency metrics. For example, UnitedHealthcare (UHC) has developed a 'star ranking' system for their providers where patients can see the ranking of a provider and determine if they want to stay with their current provider or upgrade to a higherranked provider [2]. In a world where increased cost sharing for medical care has increased the consumer's 'skin in the game', 
such a provider ranking system has the potential to be used by consumers and possibly to affect their health care cost and utilization.

Working with UHC, we obtained the provider quality and efficiency rankings posted on UHC's web site since 2006. Using claims data from enrollees representing almost 4,000 covered lives in two firms where UHC was the sole provider of health insurance and a pre-post design, we can address two research questions:

1) Did patients switch to higher-quality and more-efficient doctors when the provider rankings became available?

2) What is the effect of switching on total expenditures, out-ofpocket expenditures, and use of preventive services?

Addressing these questions identifies the likelihood that transparent provider quality and cost information will have a meaningful impact on the health care system of the United States.

\section{Background on Transparent Health Data}

The Internet has the potential to lower the costs of healthcare by distributing information to consumers. The Internet also provides a dynamic interactive medium where the consumer can seek specific information on a topic. With respect to health care, while the value of the internet for seeking health information has been documented by Baker et al. [3] little research has been published in the sixteen years since their article regarding consumer behavior towards price data and how they use it. It is unknown whether consumers understand the information they receive, gain knowledge as a consequence, and act from this knowledge. This lack of information is significant, as there are over 60 public state-based health care websites [4]. Furthermore, 111 of America's 115 largest hospitals have price information on their internet websites [5]. Despite these sites being available to the public, Mehrotra et al. show that few people price shop for their healthcare, although Kullgren, Duey and Werner have found the sites to have the potential to lower costs for the consumer $[6,7]$.

Health care costs have increased for decades. The recent promotion of transparency of health care cost and quality information by former Presidents Bush and Obama, as well as President Trump, was intended to provide information to consumers that would be difficult to obtain systematically and objectively. Provision of this information is the foundation of the consumer directed health plan (CDHP) initiative as well as the goal of developing a national health information technology infrastructure. To support the transparency initiatives, private and public insurers recently have developed and distributed tools to inform consumers about health care quality and cost. For example, Medicare's Hospital Compare project disseminates Web-based hospital performance measures collected as part of its reimbursement incentive program.

One of the key technologies enabling provider transparency initiatives is provider profiling. Provider profiling technology is nearly thirty years old. Motivated by Wennberg's and
Gittlesohn's finding of small-area variations in providers' practice styles, [8] early use of the technology has been credited anecdotally with helping to make early physician-led managed care organizations solvent by the mid- to late-1980s. In 1992, a national conference of policy makers, academics and health plans agreed on the widespread use of the technology to contain health care costs [9]. Recent innovations and policy initiatives have reinvented provider profiling. The push for health care price and quality transparency is driving public and private insurers to use redesigned provider profiling tools. Metrics for measuring quality have been created by the National Committee for Quality Assurance [10] and the Agency for Healthcare Research and Quality [11]. In addition, pharmacy-based quality measures have been developed for pharmaco-economic studies. The eventual addition of clinical data from a national health information technology infrastructure will increase the quality of the tools even more.

\section{UnitedHealthcare's Provider Rating System}

UHC was an early user of provider profiling and documented the value of the technology for improving quality of care in an early publication on these initiatives [12]. Today, these applications have evolved into a comprehensive provider rating system focused on primary care as well as specialty physicians. The goal of this system is to empower consumers and their physicians with information. The leaders of the initiative recognize that not all health care is the same and physicians may not know how they are doing compared with their peers. Furthermore, consumers want information but may not know how to get it, or how best to use it.

The provider rating system to be evaluated uses two dimensions of performance - quality and efficiency. Each dimension is represented by a star to consumers. One star denotes a highquality provider and two stars denote a high-quality and highefficiency provider. UHC was careful to not identify the highefficiency providers independent of the high-quality designation to avoid claims that consumers were being driven to low-cost providers with less than high quality. Thus, providers with no stars could also be low cost with average or low quality.

The quality and efficiency scores are created by a five-step process based on claims data available to UHC from all lines of their health insurance business:

- Twenty-four months of data are collected and analyzed on all physicians in the specialties eligible for designation.

- The quality screens are applied based on specialty and, where applicable, focus of care provision ${ }^{1}$.

- Only those physicians who meet/exceed the quality criteria are designated by a quality star and move on to the efficiency analysis.

${ }^{1} \mathrm{~A}$ focus of care provision can be a disease, specialty or treatment modality where sufficient evidence-based medicine metrics exist to assess quality of care. Also, note that quality is benchmarked to each specialty so exogenous events will not trigger changes in quality. For example, if a patient develops a condition that requires seeing a specialist such as a cardiac surgeon and cardiac surgeons as a class happen to have high quality, that event will not appear as a change in quality. 
- Episodes/procedures are analyzed for cost efficiency by benchmarking to market specialty averages and are case mix/ severity adjusted.

- Those who meet or are more efficient than market cost criteria are designated by two stars.

Once the data are synthesized, the ratings are made available to providers and consumers. Providers receive on-line performance reports with patient-level detail available for further exploration. A Medical Director is also available to discuss quality and efficiency improvement opportunities.

\section{Study Data and Methods}

Health care cost is the central measure to gauge the impact of UHC's provider rating tool. To investigate the impact of provider ratings on cost, we completed a claims-based analysis using data from UHC. The unit of analysis was continuously enrolled health plan participants over two years (one year before and one year after the quality and efficiency ratings were released). Individuals were chosen based upon the deployment of the provider rating tool within a specific UHC geographic market. Currently, UHC has claims data available for over forty million subscribers in markets that span the United States. In most markets, UHC has approximately $20 \%$ (on average) of the eligible enrollees.

To answer our research questions, we used a pre-post design where we tracked the health care cost and utilization of a specific subscriber and dependents over the two-year period from 2005 through 2006. The tool was not available to consumers in 2005, so this serves as the pre-tool base year. However, UHC collected information that enabled us to create provider rankings for 2005 and thus to calculate a difference score described below. In 2006 the tool was introduced in selected markets, and it was introduced in more markets in 2007.

Data for our study came from two large employers with over 8,000 covered lives where all the insurance contracts are managed by UnitedHealthcare. We had access to medical and pharmacy claims and enrollment data for two years: pre- and post-exposure to the provider ranking system.

2006 also was the year in which the two employers had 'full replacement' of their traditional PPO/POS health plans with CDHPs. Neither firm had prior experience with CDHPs. Firm \#2 adopted two CDHPs (a Health Reimbursement Arrangement (HRA) and a Health Savings Account (HSA)) in 2006, while Firm \#1 adopted only an HSA in 2006. Because exposure to the provider ranking system occurred simultaneously with full replacement, we cannot generalize the findings to employers that adopted the provider rankings but did not implement full replacement.

We selected employees who were enrolled in the employers' health benefits programs for two continuous years. This provided us with a cohort to identify the effects of the provider rankings. Firm \#1 had higher cohort retention with $61.6 \%$ of the first-year population also being in the second year. Firm \#2 had a lower retention rate of $47.2 \%$. These cohorts include not only the employees but their spouses and dependents. As a result, even if a firm has relatively low employee turnover, changes in coverage among spouses and dependents can substantially reduce the size of a continuous cohort. From both firms, the cohort sample had 3,928 continuously enrolled subscribers, spouses, and dependents.

The demographics of our study sample are described in Table 1. Firm \#1 has a slightly older population (34.1 years of age versus 33.9 ) and a higher share of dependents (37.3\% versus $29.5 \%$ ). Firm \#1 is also associated at baseline with a higher illness burden, as computed from claims data based on the Adjusted Clinical Group (ACG) system (Weiner et al 1991), and the presence of serious health events that could be catastrophic.

One of the critical variables for this analysis is the 'provider portfolio index' of quality and efficiency. This index is derived from UHC's provider rating system. The concept of a portfolio index is like that of a person having a portfolio of different stocks and their associated rates of return. The portfolio index works in the following fashion. A patient will see different physicians, each with a different UHC provider rating. To get an aggregate measure of the quality of the patient's providers, one needs a numeric score for each provider; then one weights that score by the extent of 'exposure' to a given provider, measured by either reimbursement or service contact with a physician. For example, if a patient sees two physicians where one has a quality rating of 3 and the other a rating of 1 ( 3 is the best score and 1 is the worst possible score), an average un-weighted portfolio score would be 2.0. However, if the patient saw the 1-rated physician for $90 \%$ of all expenditures and the 3 -rated physician for $10 \%$ of all expenditures, the reimbursement-weighted portfolio score would be 1.2. If the percentages were reversed, the score would be 2.8. Thus, simply taking the average without accounting for exposure could lead to different results. An alternative and more traditional approach is to identify a usual source of care and then associate the provider rating score with that physician. A concern with this method is that patients can see an array of different providers with significant variation in their ratings, but the usual source of care approach assigns them to only one of these providers. The portfolio approach considers the effect of all providers with variation in efficiency and quality.

To use the portfolio approach, we needed a numeric system that would create the data for a weighted portfolio score. We transposed UHC's provider star rating system in the following way:

Table 1 Study sample demographics.

\begin{tabular}{|l|l|l|}
\hline Variable & Firm 1 & Firm 2 \\
\hline Age (years) & 34.118 & 33.928 \\
\hline Female=1, else Female=0 & 0.527 & 0.439 \\
\hline Baseline Illness Burden & 3.406 & 2.472 \\
\hline Catastrophic Shock=1, else 0 & 0.268 & 0.234 \\
\hline Enrollee is subscriber=1, else 0 & 0.375 & 0.445 \\
\hline Enrollee is spouse=1, else 0 & 0.252 & 0.258 \\
\hline Enrollee is dependent=1, else 0 & 0.373 & 0.295 \\
\hline Observations (total=3,928) & 2,464 & 1,464
\end{tabular}


Value Situation - Star Rating; Proportion of MDs Ranked²:

1 No provider rating 3 ; 89.4\%,

2 Good quality rating only; $1.9 \%$,

3 Good quality and efficiency ratings; $8.7 \%$.

The rationale for placing quality over efficiency is the patient's perspective. Given that most health care costs from a significant unplanned or discretionary procedure are borne by the insurer/ employer and not the patient, we assume patients would care more about quality than efficiency.

With a patient-level provider portfolio score, we can measure any changes in the patient's portfolio score from the pre-ranking year to the post-ranking year. A reduction in the portfolio score might be due to lack of access or an overriding desire to maintain a relationship with a provider, regardless of quality or efficiency. If a patient stayed with the same provider there should be no change in the score unless that provider got worse. An increase in the portfolio score would indicate increased interest in physicians who practice with high quality and are efficient.

Our econometric method to answer question \#1 is simply a nonlinear regression where we identify the factors associated with an improvement in the provider portfolio score. Specifically, the dependent measure equals 1 if the difference between the 2006 physician portfolio score and the 2005 physician portfolio score is greater than 0 . The dependent measure is 0 otherwise. Factors considered affecting the change in portfolio are age, gender, firm, contract holder status (employee, spouse, or dependent), baseline illness burden, and the catastrophic health shock variable ${ }^{4}$.The provider portfolio rating was weighted based on total allowed expenditures which include those paid by the health plan and the consumer.

To examine the second research question, we test whether patients who upgraded their provider portfolios had statistically significant differences in health care spending and the use of preventive services. We used a difference-in-differences regression model to test the impact on cost of those who switched or remained with their physicians using methods similar to those used in prior CDHP empirical analyses $[13,14]$.

We also used descriptive statistics to see the scale of the switching effect as well as the cost differences for patients who switched in a manner consistent with the star rating and with those who did not switch. Analytic files with cost as well as preventive care measures were constructed based on claims data provided by UHC. We used a set of preventive care measures developed in previous collaborative research with clinicians at the University of Pennsylvania [15].

${ }^{2}$ This proportion is based on the physician/patient combinations of our study population.

${ }^{3}$ No provider rating is associated with providers where there was insufficient data available for scoring or where a provider did not meet the criteria for a quality star.

${ }^{4}$ Overall illness burden is based on a count of Ambulatory Diagnostic Groups (ADGs) in the base year of observation and is derived from an algorithm described by Weiner et al. (Weiner J.P., Starfield, B.H., Steinwachs D.M., Mumford L.M., (1991). Development and Application of a Population-oriented Measure of Ambulatory Care Case-mix, Medical Care. 29(5), 452-72.). Catastrophic shock is a concurrent-year variable based on the presence of an ADG where the patient had a major acute care event, cancer diagnosis, injury or trauma.

\section{Results}

The first step in our empirical analysis was to generate the provider portfolio ratings. We weighted the portfolio ratings by three different patient and year-specific variables: the unique number of provider visits of a patient; the allowed charge amount for the patient; and the out-of-pocket expenditures of the patient. Table 2 provides the results of these ranking methodologies. The first set of variables in the table corresponds to the secondyear portfolio score by each of three methods used. Note that both firms have average scores above 1 (the lowest value). The second set of rows in Table 2 is the change between year 1 and year 2 in provider portfolio ratings. Note that the allowed chargeweighted and visit-weighted portfolio scores decreased slightly for Firm \#1. The last set of rows in the table is associated with the variable we use in our multivariate analysis: a 0/1 variable for whether a person's provider portfolio improved from one year to the next. Although the out-of-pocket expenditure-weighing method is associated with the greatest improvement in portfolio rankings, we choose the median method in terms of impact weighting by allowed charges.

The Year 2 portfolio scores are low (averaging around 1.5) due to the large number of physicians seen by the study population that were not ranked by UHC or did not have a quality rating or quality plus efficiency rating. These least-ranked physicians have a score of 1 as opposed to a score of 2 for physicians with one star for high quality or a score of 3 for physicians ranked for two stars on high quality and efficiency. The dominant score in the distribution of physician of MD scores listed above is 1 .

In Table 3, we present the bivariate results associated with a change in provider portfolio ratings on expenditures and preventive care use. The two firms experienced a major change in benefit design with full replacement of PPO/POS plans by a $\mathrm{CDHP}(\mathrm{s})$. As noted above, we use the change in portfolio from an allowed charge weighting method to identify the impact of the ranking system at each firm ${ }^{5}$. In the case of Firm $\# 1$, total expenditures increased from $\$ 2,358$ to $\$ 3,425$ for patients with

Table 2 Provider portfolio rankings by weighting type.

\begin{tabular}{|l|c|c|}
\hline \multicolumn{3}{|c|}{ Average Values } \\
\hline Variables & Firm 1 & Firm 2 \\
\hline Year 2 Portfolio Score & & \\
\hline Visit Weighted & 1.648 & 1.476 \\
\hline Allowed Charges Weighted & 1.556 & 1.446 \\
\hline Out-of-pocket \$\$ Weighted & 1.237 & 1.029 \\
\hline Year 2 - Year 1 Portfolio Rating Delta & & \\
\hline Visit Weigted & -0.009 & 0.010 \\
\hline Allowed Charges Weighted & -0.001 & 0.044 \\
\hline Out-of-pocket \$ Weighted & 1.143 & 0.537 \\
\hline Positive Change in Score = 1, else 0 & & \\
\hline Visit Weigted & 0.330 & 0.256 \\
\hline Allowed Charges Weighted & 0.341 & 0.268 \\
\hline Out-of-pocket \$\$ Weighted & 0.658 & 0.435 \\
\hline
\end{tabular}

${ }^{5}$ We chose to weight by allowed charges because our interest is in the effect of the star system on resource use. This is best measured by allowed charges, some of which will be paid by the member and some by the plan. 
Table 3 Bivariate provider portfolio ratings changes with cost and preventive use.

\begin{tabular}{|c|c|c|c|c|c|c|c|c|}
\hline & \multicolumn{4}{|c|}{ Provider Portfolio Negative or Neutral Change } & \multicolumn{4}{|c|}{ Provider Portfolio Positive Change } \\
\hline & \multicolumn{2}{|l|}{ Firm 1} & \multicolumn{2}{|l|}{ Firm 2} & \multicolumn{2}{|l|}{ Firm 1} & \multicolumn{2}{|l|}{ Firm 2} \\
\hline & Year 1 & Year 2 & Year 1 & Year 2 & Year 1 & Year 2 & Year 1 & Year 2 \\
\hline Total Expenditures & $\$ 2,358$ & $\$ 3,425^{* * *}$ & $\$ 1,984$ & $\$ 2,091$ & $\$ 5,188$ & $\$ 4,293^{*}$ & $\$ 4,157$ & $\$ 3,124^{*}$ \\
\hline Consumer Medical Expenditures & $\$ 87$ & $\$ 344^{* * *}$ & $\$ 259$ & $\$ 492^{* * *}$ & $\$ 149$ & $\$ 455^{* * *}$ & $\$ 583$ & $\$ 721^{* *}$ \\
\hline Consumer Pharmacy Expenditures & $\$ 48$ & $\$ 238^{* * *}$ & $\$ 144$ & $\$ 175^{*}$ & $\$ 72$ & $\$ 385^{* * *}$ & $\$ 311$ & $\$ 435^{* * *}$ \\
\hline Preventive Visits & 0.29 & 0.29 & 0.12 & 0.19 & 0.445 & 0.474 & 0.247 & 0.258 \\
\hline Colonoscopy Screenings & 0.210 & 0.239 & 0.131 & 0.111 & 0.262 & $0.185^{* *}$ & 0.256 & $0.118^{* * *}$ \\
\hline
\end{tabular}

Table 4 Attributes associated with positive changes in provider portfolios.

\begin{tabular}{|c|c|c|c|c|c|c|}
\hline \multirow[t]{3}{*}{ Variables } & \multicolumn{6}{|c|}{ Provider Rating Portfolio Weighting Methodology } \\
\hline & \multicolumn{2}{|l|}{ Visit } & \multicolumn{2}{|c|}{ All Allowed $\$ \$ \$ \$ \$$} & \multicolumn{2}{|c|}{ Out of Pocket $\$ \$$} \\
\hline & Coefficient & $\operatorname{Pr}>$ ChiSq & Coefficient & Pr>ChiSq & Coefficient & Pr>ChiSq \\
\hline Intercept & -1.0408 & $<0.0001$ & -1.0016 & $<0.0001$ & 0.3635 & 0.0011 \\
\hline Age (years) & 0.0049 & 0.026 & 0.0038 & 0.0782 & -0.0104 & $<0.0001$ \\
\hline Female $=1$, else 0 & 0.0973 & 0.0298 & 0.0777 & 0.0825 & 0.1378 & 0.0014 \\
\hline Baseline Illness Count & 0.0995 & $<0.0001$ & 0.1056 & $<0.0001$ & 0.1636 & $<0.0001$ \\
\hline Catastrophic Shock=1, else 0 & 0.1836 & 0.0004 & 0.1237 & 0.0179 & 0.3412 & $<0.0001$ \\
\hline Firm 2=1, else 0 & -0.1221 & 0.009 & -0.1161 & 0.0129 & -0.5535 & $<0.0001$ \\
\hline Enrollee is spouse $=1$, else 0 & -0.0430 & 0.4221 & -0.0252 & 0.6372 & -0.0894 & 0.0994 \\
\hline Dependent enrollee $=1$, else 0 & -0.2919 & 0.0014 & -0.3106 & 0.0007 & -0.6630 & $<0.0001$ \\
\hline
\end{tabular}

a negative or neutral provider portfolio change, but decreased from $\$ 5,188$ to $\$ 4,293$ for those with a positive provider portfolio change. Similar patterns were observed in Firm \#2, with increases from $\$ 1,984$ to $\$ 2,091$ for patients with a negative or neutral provider portfolio change and decreases from $\$ 4,157$ to $\$ 3,124$ for those with a positive provider portfolio change. Patients with positive changes had higher baseline spending in both firms an indication of the need to control for baseline illness burden and other factors that determine the level of spending across patients.

Out-of-pocket medical expenditures have different patterns compared with overall expenditures. Out-of-pocket spending increased for both types of patients in both firms. This is due, most likely, to the changes in the health plans in both firms in 2006. Similar patterns were observed for consumer out-ofpocket pharmacy spending.

With respect to preventive visits, patients in both firms with positive provider portfolio changes had fewer colonoscopies in year 2 than in year 1 . Other changes in preventive visits and colonoscopies were not statistically significant.

The attributes associated with positive changes in provider portfolios are described in Table 4. Here we look at the results of three logistic regressions, each using a different weighting strategy for identifying a positive change in the provider portfolio. The middle set of results that is boxed represents the weighted by allowed charges strategy we use for this analysis. The table is useful to identify the attributes of patients associated with positive changes in provider portfolios. Across all methodologies we see a positive relationship with female gender. Age has a positive relationship for visits and allowed charge-weighted portfolio scores and a negative relationship with out-of-pocket expenditure-weighted portfolio scores. Those who are more ill, either due to a higher illness burden or a catastrophic medical event, have greater likelihood of improving their provider portfolio. In all weighting methodologies, spouses and dependents have less improvement in their provider portfolio than the insurance contract holder.

In Tables 5 through 7, we present two models of the effects of a positive change in provider portfolio on expenditure. Model 1 uses a 'dummy' variable defined as 1 if there was a positive change in the patient's provider portfolio between year 1 and year 2 , and 0 if there was not a positive change. Model 2 includes an interaction term between the illness burden metric and the dummy variable indicating a positive change in provider portfolio. We used Mode1 2 to examine whether improvement in PPI may have different impacts for people who have low and high illness burdens. In Table 5, we examine the effect of the change in provider portfolio on the change in total spending. In model 1 , the effect is largely negative and statistically significant, suggesting an overall cost savings from provider portfolio improvement. In model 2, the portfolio change variable is now positive and insignificant. However, the interaction of illness burden and provider portfolio change is negative and significant. This suggests patients with a greater illness burden have lower expenditures if they receive care from a set of providers where there was improvement in the provider portfolio. As expected, age and the presence of a catastrophic illness shock have statistically significant and positive effects on the change in total expenditures.

Tables 6 and $\mathbf{7}$ present the effect of a positive change in provider portfolio on the change in consumer out-of-pocket expenditures for medical care and pharmaceuticals, respectively. We find 
Table 5 Impact of a positive change in provider portfolio on change in total expenditures.

\begin{tabular}{|c|c|c|c|c|}
\hline \multirow[t]{2}{*}{ Change in Total Expenditures } & \multicolumn{2}{|l|}{ Model 1} & \multicolumn{2}{|l|}{ Model 2} \\
\hline & Coefficient & $\operatorname{Pr}>|t|$ & Coefficient & $\operatorname{Pr}>|t|$ \\
\hline Intercept & 804.954 & 0.227 & 89.754 & 0.894 \\
\hline Age (years) & 15.353 & 0.226 & 21.021 & 0.097 \\
\hline Female $=1$, else 0 & 192.379 & 0.458 & 121.538 & 0.638 \\
\hline Baseline Illness Burden & -370.544 & $<0.0001$ & -176.619 & 0.005 \\
\hline Catastrophic Shock $=1$, else 0 & 3323.816 & $<0.0001$ & 3293.081 & $<0.0001$ \\
\hline Firm 2=1, else 0 & -927.401 & 0.001 & -874.774 & 0.001 \\
\hline Enrollee is spouse $=1$, else 0 & 593.991 & 0.065 & 540.374 & 0.092 \\
\hline Enrollee is dependent $=1$, else 0 & -316.554 & 0.545 & -155.532 & 0.766 \\
\hline Provider Portfolio improvement $=1$, else 0 & -1593.317 & $<0.0001$ & 709.520 & 0.145 \\
\hline Portfolio Change $\times$ IIIness Burden & & & -642.657 & $<0.0001$ \\
\hline Adjusted R-Square & 0.047 & & 0.055 & \\
\hline
\end{tabular}

Table 6 Impact of a positive change in provider portfolio on change in OOP medical expenditure.

\begin{tabular}{|c|c|c|c|c|}
\hline \multirow[t]{2}{*}{ Change in Consumer Out-of-Pocket Medical Expenditures } & \multicolumn{2}{|l|}{ Model 1} & \multicolumn{2}{|l|}{ Model 2} \\
\hline & Coefficient & $\operatorname{Pr}>|t|$ & Coefficient & $\operatorname{Pr}>|t|$ \\
\hline Intercept & 362.619 & $<0.0001$ & 323.352 & $<0.0001$ \\
\hline Age (years) & -1.612 & 0.112 & -1.300 & 0.200 \\
\hline Female $=1$, else 0 & 64.858 & 0.002 & 60.968 & 0.003 \\
\hline Baseline Illness Burden & -16.422 & 0.000 & -5.774 & 0.253 \\
\hline Catastrophic Shock=1, else 0 & 353.670 & $<0.0001$ & 351.982 & $<0.0001$ \\
\hline Firm 2=1, else 0 & -65.964 & 0.002 & -63.075 & 0.003 \\
\hline Enrollee is spouse $=1$, else 0 & -20.570 & 0.423 & -23.513 & 0.359 \\
\hline Enrollee is dependent $=1$, else 0 & -226.746 & $<0.0001$ & -217.905 & $<0.0001$ \\
\hline Provider Portfolio improvement $=1$, else 0 & -30.728 & 0.177 & 95.706 & 0.014 \\
\hline Portfolio Change $\times$ Illness Burden & & & -35.284 & $<0.0001$ \\
\hline Adjusted R-Square & 0.063 & & 0.067 & \\
\hline
\end{tabular}

different impacts of the provider portfolio change on these two types of spending. For out-of-pocket medical expenditures, there is a negative impact from the portfolio change variable's interaction with the patient's illness burden in model 2 . In model 1 , the effect of provider portfolio improvement is also negative but not statistically significant at the $p<0.05$ level. The catastrophic shock variable is associated with the largest positive impact on the change in out-of-pocket medical expenditures.

For pharmaceutical services, the effect is quite different. In Table 7 there is a positive and significant effect of provider portfolio change in model 1 . In model 2 , the interaction of illness burden and change in provider portfolio is small and statistically insignificant. This suggests that for pharmaceutical services, there may be less value in changing to providers who have a higher star rating.

In Tables $\mathbf{8}$ and 9, we examine the effect of a change in provider portfolio on the change in use of preventive services. In Table $\mathbf{8}$, the portfolio change variable shows a positive and significant relationship with the change in preventive visits, after accounting for age, gender and health status. However, for colonoscopy screening the result is quite different. As seen in Table $\mathbf{9}$, a positive change in provider portfolio is associated with a substantial decrease in colonoscopy screening and the result is statistically significant at the $p<0.001$ level.
We performed an additional analysis (not reported here) as a specification check on our main models. This analysis included an interaction of female and contract-holder status in the provider portfolio improvement models. We wanted to see this because the other results indicated that females were more likely than males and contract-holders more likely than spouses and dependents, to improve their provider portfolios. These relationships might not have been estimated accurately because females were less likely than males to be contract-holders $(39.4 \%$ of females versus $42.7 \%$ of males). However, the interaction term was not significant, and it did not affect the sign or significance of any other variable.

\section{Discussion}

This analysis has two key findings. The answer to our first research question - who uses the provider rating system - is that older, sicker individuals and women are more likely to use the system. The second finding, addressing our second research question, is that the UHC provider rating system appears to have a negative impact on expenditures. The effect is found for total expenditures and out-of-pocket medical spending, but not for out-of-pocket pharmacy costs.

With respect to prevention, the story is more mixed. Overall preventive visits go up when the patient has an improved 
Table 7 Impact of a positive change in provider portfolio on change in drug OOP expenditure.

\begin{tabular}{|c|c|c|c|c|c|c|}
\hline \multirow[t]{3}{*}{$\begin{array}{l}\text { Change in Consumer Out-of-Pocket Pharm } \\
\text { Expenditures }\end{array}$} & & & & & & \\
\hline & \multicolumn{3}{|c|}{ Model 1} & \multicolumn{3}{|c|}{ Model 2} \\
\hline & Coefficient & T-Stat & $\operatorname{Pr}>|t|$ & Coefficient & T-Stat & $\operatorname{Pr}>|t|$ \\
\hline Intercept & 77.289 & 60.280 & 0.004 & 76.935 & 60.280 & 0.005 \\
\hline Age (years) & 2.632 & 11.660 & $<.0001$ & 2.634 & 11.660 & $<.0001$ \\
\hline Female $=1$, else 0 & 22.760 & 4.840 & 0.030 & 22.725 & 4.840 & 0.031 \\
\hline Baseline IIIness Burden & 18.363 & 43.850 & $<.0001$ & 18.459 & 43.850 & $<.0001$ \\
\hline Catastrophic Shock=1, else 0 & -19.260 & 13.880 & 0.128 & -19.276 & 13.880 & 0.128 \\
\hline Firm 2=1, else 0 & -152.306 & -2.790 & $<.0001$ & -152.280 & -2.790 & $<.0001$ \\
\hline Enrollee is spouse $=1$, else 0 & -27.280 & 2.790 & 0.036 & -27.307 & 2.790 & 0.036 \\
\hline Enrollee is dependent $=1$, else 0 & -55.067 & -0.200 & 0.010 & -54.987 & -0.200 & 0.010 \\
\hline Provider Portfolio improvement $=1$, else 0 & 51.635 & 10.730 & $<.0001$ & 52.776 & 10.730 & 0.008 \\
\hline Portfolio Change * Illness Burden & & -8.000 & & -0.319 & -8.000 & 0.944 \\
\hline Adjusted R-Square & 0.134 & & & 0.134 & & \\
\hline
\end{tabular}

Table 8 Impact of a Positive Change in Provider Portfolio on Change in Preventive Visits.

\begin{tabular}{|c|c|c|}
\hline Any Preventive Visits & Coefficient & $\operatorname{Pr}>\mid \mathbf{t}$ \\
\hline Intercept & 0.031 & 0.0385 \\
\hline Age(Years) & 0.000 & 0.903 \\
\hline Female $=1$, else 0 & 0.006 & 0.667 \\
\hline Baseline IIIness Burden & -0.017 & $<.0001$ \\
\hline Catastrophic Shock=1, else 0 & 0.007 & 0.666 \\
\hline Firm 2=1, else 0 & -0.001 & 0.949 \\
\hline Enrollee is spouse $=1$, else 0 & -0.006 & 0.735 \\
\hline Enrollee is dependent $=1$, else 0 & 0.010 & 0.727 \\
\hline Provider Portfolio improvement $=1$, else 0 & 0.050 & 0.001 \\
\hline Adjusted R-square & 0.01 & \\
\hline
\end{tabular}

provider portfolio. We do not see the same effect for colonoscopy procedures, however. While it is possible that the decline in colonoscopies could be due to switching to a less-expensive screening test, this type of switching should be similar among those who improved their provider portfolio scores and those who did not. Thus, the decline in colonoscopies is an unexpected and problematic finding that warrants further monitoring.

The study has several limitations. First, it is based on the provider ranking system implemented by one insurer, UnitedHealthcare, in one setting, full replacement of two firms' traditional health plans with CDHPs. Other systems and settings could be associated with different results. For example, consumers might save less money from switching to cost-effective providers in settings where the financial rewards from switching are not as great. A further limitation of the study are factors we cannot observe that may affect patient use of information in care seeking. Specifically, we do not observe potential factors that could change patient care seeking behavior such as socio-economic status, income or education. As a modest control for such factors, the study populations are internally consistent to two moderately sized firms within specific geographic locations where education and income may be less variable.

We focused on a limited set of outcome variables in this analysis that were most critical for the initial deployment of the transparency tool. While we observe a reduction in total health
Table 9 Impact of a positive change in provider portfolio on change in colonoscopy screening.

\begin{tabular}{|c|c|c|c|}
\hline Change in Colonoscopy Screening & Coefficient & T-Stat & $\operatorname{Pr}>|t|$ \\
\hline Intercept & 0.384 & 60.280 & 0.002 \\
\hline Age (years) & -0.005 & 11.660 & 0.024 \\
\hline Female $=1$, else 0 & -0.001 & 4.840 & 0.982 \\
\hline Baseline Illness Burden & -0.019 & 43.850 & 0.001 \\
\hline Catastrophic Shock=1, else 0 & -0.004 & 13.880 & 0.894 \\
\hline Firm $2=1$, else 0 & -0.074 & -2.790 & 0.014 \\
\hline Enrollee is spouse $=1$, else 0 & 0.007 & 2.790 & 0.803 \\
\hline Provider Portfolio improvement $=1$, else 0 & -0.112 & 10.730 & $<0.0001$ \\
\hline Adjusted R-Square & 0.029 & & \\
\hline
\end{tabular}

expenditures, we are unable to ascertain whether that was more a function of changes in physician or hospital expenditures. Future analyses should examine additional variables such as specialty care visits as well as emergency room services. Outcome metrics such as process quality of care measures, e.g. HbA1c services for diabetics or 30 day hospital readmissions, will be valuable additions for future analyses.

Another important caveat is that we do not actually know if enrollees accessed the rating system. This is due to lack of a 'login' feature to track those who saw the provider rankings and how much time they spent viewing certain providers. While this could be an opportunity for future research with a login feature, the one virtue of an untraceable system is that we have sufficient information to account for a potential selection effect of the patients. Although this bias could be present, we cannot observe the direction or occurrence and thus we account for it in our statistical methods. It must also be noted that a limitation is the age of the data in this study. Although the data are old study is old and the program has had major updates, this UnitedHealthcare program still provides a unique insight on provider ranking systems. Furthermore, the findings suggest positive value in recent transparency initiatives by the federal government $[16,17]$ and Congress [18]. We hope to continue our research if these initiatives move forward with far larger sample sizes and better accounting for socioeconomic factors. The lack 
of qualitative research on how and to what extent consumers use price data is also a limitation of this paper. This information is difficult to find as some studies have found that few people shop for healthcare prices [19].

The study has three significant policy implications. First, it provides evidence that consumers will likely care about provider-level comparative effectiveness information. Given the substantial investment in comparative effectiveness in the American Recovery and Reinvestment Act of 2009 that is targeted toward effectiveness information based on secondary data sources like claims, this study supports the federal expenditure.

The second implication is that if consumers can use administrative data for provider rankings, the future availability of clinical data through meaningful electronic medical records will enhance the value of transparency initiatives. The HITECH Act's requirement for meaningful physician and hospital electronic record systems will promote the collection of clinical quality data such as $\mathrm{HbA1C}$ tests for diabetics and blood pressure for hypertensive patients. These data could be the basis for future provider ranking initiatives.

Third, state and federal initiatives to provide information on provider quality and efficiency are likely to have value. Furthermore, public Internet distribution of provider quality rankings similar to what United Healthcare used, as opposed to a proprietary system, will be easier to implement and based on our results, likely to have positive heath and financial impacts on consumers. These financial impacts have the potential to save $\$ 36$ billion in overall healthcare spending [20].

\section{Conclusion}

We looked for the effect of provider quality and efficiency rankings on expenditures and use of preventive services. The value of this analysis is to show that consumers exhibit behavior that suggests they may use these rankings to engage in retail shopping for health care services. Other dependent variables can be used as well as more years of information and different benefit designs. Other insurers' provider transparency systems could be examined and compared as well. Regarding policy implications, consumer driven advocates' campaign for transparency appears

\section{References}

1 Herzlinger R (2004) Consumer Driven Health Care: Implications for Providers, Payers, and Policy-Makers. Jossey-Bass.

2 United Health Group (2004) Episode Treatment Group white paper. URL: http://www.symmetry-health.com/ETGTut_Desc1.htm.

3 Baker L, Wagner TH, Singer S, Bundorf MK (2003) Use of the Internet and E-mail for Health Care Information: results from a national survey. JAMA 289: 2400-2406.

4 Kullgren JT, Duey KA, Werner RM (2013) A Census of State Health Care $P$ rice Transparency Websites. JAMA 309: 2437-2438.

5 Quinto A, Shendruk A (2019) US Hospitals are now required to post prices online. Good luck finding them. Quartz. to have merit. Although the results were quite early, they show promise and suggest that consumers can process additional information on price and quality to gain more value from their health insurance benefits.

\section{Declarations}

Ethics approval and consent to participate: Non-applicable. No patient medical records were used.

Consent to publish: Non-applicable. No patient medical records were used.

Availability of data and materials: The data used were made available by UnitedHealthcare (UHC). UHC has made their data available to qualified researchers through the Health Care Cost Institute and Optum Labs.

Competing interests: None of the authors have competing interests with the data presented in this analysis.

Funding: This research was supported by the Robert Wood Johnson Foundation's Health Care Financing and Organization Initiative and the US Department of Health and Human Services through contract HHSP23320054301ER.

Authors' contributions: Parente (initial draft, statistical programming, editing); Feldman (statistical consultation, hypothesis testing, editing); Sandy (data provision, initial draft, expert review of clinical content, editing).

\section{Acknowledgements}

We acknowledge the invaluable context suggestions made by Alexander Shultz. Trusted third party data security services were provided by Lisa Tomai. Computer programming and analytic support were provided by Altarum, Inc. Project coordination and institutional review board preparation were facilitated by Ruth Taylor. Mona Shah, Regina Levin and Meredith Baratz facilitated data access and support. Comments from members of the Health Care group of the National Bureau of Economic Research, especially from Jon Gruber and David Cutler, helped to sharpen this work.

Disclaimer: The research presented in this article is the product of the researchers only and does not represent the views of associated employers, health plans and financing organizations.

6 Mehrotra A, Katie MD, Sinaiko AD, Sood N (2017) Americans Support Price Shopping For Health Care, But Few Actually Seek Out Price Information. Health Affairs 36: 1392-1400.

7 Kullgren JT, Duey KA, Werner RM (2013) A Census of State Health Care Price Transparency Websites. JAMA 309: 2437-2438.

8 Wennberg J, Gittelsohn A (1973) Small area variations in health care delivery. Science 182: 1102-1108.

9 Physician Payment Review Commission Conference on Profiling Washington (1992) DC: Physician Payment Review Commission pp: 2-92.

10 National Committee on Quality Assurance. HEDIS 2007 Measure Set, http://web.ncqa.org/Portals/0/HEDISQM/HEDIS2007/MeasuresList. pdf. 
11 Agency for Healthcare Research \& Quality. National Healthcare Quality Report Parameters, http://www.qualitymeasures.ahrq.gov/ resources/summaryarchive.aspx\#updated.

12 Leatherman S, Peterson E, Heinen L, Quam L (1991) Quality Screening and Management Using Claims Data in a Managed Care Setting, Quality Review Bulletin 17: 348-359.

13 Parente ST, Feldman R, Chen S (2008) The Effects of a Consumer Driven Health Plan on Pharmaceutical Spending and Utilization: Do Three-Tier Plans Have a Competitor? Health Services Research 43: 1542-1556.

14 Feldman R, Parente ST, Christianson JB (2007) Consumer Directed Health Plans: New Evidence on Spending and Utilization, Inquiry 44: 26-40.

15 Pollack CE, Mallya G, Polsky D (2008) The Impact of ConsumerDirected Health Plans and Patient Socio-economic Status on
Physician Recommendations for Colorectal Cancer Screening. Journal of General Internal Medicine 23: 1595-1601.

16 Armour S (2019) Trump Administration Preparing Executive Order on Health-Cost Disclosure. The Wall Street Journal.

17 Bluth R Sens. Alexander, Murray (2019) Health Legislation Targeting High Bills, Drug Costs.

18 Parente ST, Tomai L (2019), Medicare Oncology Care Bundle Variation in Cost and Use. J Health Med Econ Vol.5, No.1:1.

19 Mehrotra A, Katie M. Dean, Sinaiko AD, Sood N (2017) Americans Support Price Shopping For Health Care, But Few Actually Seek Out Price Information. Health Affairs 36: 1392-1400.

20 Christensen HS, Eric F, Maffett MG (2013) The Only Prescription is Transparency: The Effect of Charge-Price-Transparency Regulation on Healthcare Prices, pp: 14-33. 